\title{
Quando as mulheres herdam: uma análise de gênero dos fenômenos de linhagens na Ásia Meridional ${ }^{1}$
}

\author{
Virginie Dutoya
}

\begin{abstract}
Resumo: A importância das "famílias políticas" é uma característica conhecida nos regimes da Ásia Meridional. 0 papel da hereditariedade nesta área se torna mais notável, pois esse fenômeno dá lugar às mulheres em contextos que de outra forma são desfavoráveis para elas. Assim, a família, um lugar marcado pela (re)produção das representações e das hierarquias de gênero constitui um canal de acesso ao poder político para as mulheres do sul da Ásia. O estudo dos casos da Índia e do Paquistão nos permitem analisar a dinâmica da transmissão intrafamiliar dos mandatos parlamentares a partir de uma perspectiva de gênero. O levantamento quantitativo e qualitativo das mulheres parlamentares desde 1947 em ambos os países destaca as possibilidades, mas também as restrições que representam os fenômenos da hereditariedade política para as mulheres. Esta análise de gênero permite captar a complexidade do entrelaçamento das relações de poder familiar, social e político.
\end{abstract}

\section{Plano do artigo}

1. Família e política na Índia: quadro metodológico e empírico

\section{Quando as mulheres herdam: gênero, parentesco e poder político}

Em que contextos as mulheres herdam um mandato?

Transmissões femininas, masculinas ou de gênero?

\section{Da legitimidade familiar à legitimidade democrática}

A família como um recurso

Condições e limites da legitimidade familiar

O estigma da "brigada das filhas e das esposas"

\section{Sobre a autora \\ Virginie Dutoya}

Pesquisadora de Ciência Política no CNRS (Centro Emile Durkheim). O seu trabalho atual centra-se nos problemas das mulheres na Índia e no Paquistão e na sua representação política numa perspectiva comparada. Sobre o tema da representação política das mulheres na Ásia Meridional, ela publicou recentemente "Um pedido feito em favor das mulheres? Cotas e representação política das mulheres na Índia e no Paquistão (1917-2010)" (Revista Francesa de Ciência Política, 26 (1), 2016, p. 49-70) e A Representação da Mulher nos Parlamentos da Índia e do Paquistão (Paris: Dalloz, 2014).

v.dutoya@sciencespobordeaux.fr

\footnotetext{
${ }^{1}$ Tradução livre de Ana Vanali. Texto original «Quand les femmes héritent: une analyse genrée des phénomènes lignagers en Asie du Sud», Critique internationale, vol. 73, no. 4, 2016, p. 19-36. Disponível em https://www.cairn.info/revue-critiqueinternationale-2016-4-page-19.htm. Acesso 25.outubro.2017. Autorização para a publicação da tradução cedido por Catherine Burucoa, responsável da Revista Critique Internationale (Sciences Po, Centre de Recherches Internationales) no dia 15 de novembro de 2017.
} 


\title{
Quando as mulheres herdam: uma análise de gênero dos fenômenos de linhagens na Ásia Meridional
}

\author{
Virginie Dutoya
}

A importância dos herdeiros nos sistemas políticos na Ásia Meridional é um fenômeno bem conhecido, embora não seja de modo algum específico para esses países. Índia, Paquistão, Bangladesh, Nepal ou Sri Lanka foram ou são atualmente dirigidos por filhas ou filhos, ou ainda por viúvas (e um viúvo) de ex-líderes, embora o sistema eleitoral fosse e seja sempre aberto e competitivo. Além desses casos de sucessão, a vida política no sul asiático pode ser descrita como de família, já que antes mesmo de morrer, muitos homens e mulheres políticos não hesitam em colocar seus entes queridos no tabuleiro político. Nesses países, o papel da hereditariedade e da família na política é ainda mais notável à medida que esses fenômenos tradicionalmente costumam compartilhar belas mulheres, enquanto historicamente a presença delas em instituições políticas foi fraca².

O caso dessas "herdeiras" é paradoxal. De fato, se sua família lhes dá acesso a um mandato político e, portanto, a uma posição (em aparência) de poder, a instituição família também é um espaço fortemente bicategorizado e hierárquico, onde até mesmos a função reprodutiva das mulheres é particularmente controlada. Além disso, a família é patrilinear e a preferência pelos filhos é forte 3 . A este respeito, o gênero, enquanto uma ferramenta teórica e metodológica permite compreender o processo de diferenciação e hierarquização dos sexos, sendo uma categoria não apenas "útil"4, mas também necessária para a análise dos fenômenos de transmissão familiar do poder político. No entanto, essa perspectiva foi até o momento pouca integrada ao estudo desse fenômeno, inclusive na Ásia Meridional ${ }^{5}$.

\footnotetext{
2 DUTOYA, Virginie. Representação das mulheres nos parlamentos da Índia e do Paquistão. Paris: Dalloz, 2014.

${ }^{3}$ UBEROI, Patricia (org). Família, parentesco e casamento na Índia. Nova Deli: Oxford University Press, 1993.

${ }^{4}$ SCOTT, Joan W. "Gênero: uma categoria útil de análise histórica". In: The American Historical Review, 91 (5), 1986, p. 1053-1075.

${ }^{5}$ Um livro editado por Claudia Derichs e Mark Thompson levanta a questão dos vínculos entre as dinastias e a liderança feminina na Ásia, incluindo a Ásia Meridional. Contudo, o livro se concentra na biografia de alguns grandes herdeiros, sem analisar sistematicamente a herança política feminina. DERICHS, Claudia e THOMPSON, Mark R. (orgs). Dinastias e líderes políticos femininos na Ásia: gênero, poder e pedigree. Zürick: Lit Verlag, 2013. No caso da Índia, se a importância das herdeiras é frequentemente mencionada, Romain Carlevan é o primeiro (a nosso conhecimento) a ter um profundo interesse por essa questão que está presente em parte de sua tese (em curso) sobre famílias políticas no norte da índia. Agradeço-lhe por compartilhar alguns dos seus resultados. Devemos também mencionar o capítulo muito recente de Amrita Basu, "Mulheres, dinastias e democracia na Índia", em CHANDRA, Kanchan (org). Dinastias democráticas: Estado, partido e família na política da Índia contemporânea. Nova York: Cambridge University Press, 2016, p. 136-172.
} 
Nossa proposta é questionar os mecanismos de transmissão familiar dos mandatos políticos parlamentares no sul da Ásia, sob a perspectiva de gênero. A Índia é o único país da região onde um número significativo de mulheres foi eleito em um período de tempo suficientemente longo para que seja possível apreender os fenômenos de linhagens em profundidade. Então nos concentraremos neste estudo de caso, mesmo se os países vizinhos, em particular o Paquistão, sejam pontualmente mobilizados como exemplos. O caso indiano não é totalmente generalizável para a Ásia Meridional, mas uma série de pontos de convergência sugere que os fenômenos observados na Índia não estão sem relações com aqueles que podem ser encontrados no Paquistão, em Bangladesh, no Nepal e em Sri Lanka. Nesses países, as mulheres atingiram as funções mais elevadas pelo viés das sucessões mais ou menos diretas. Além disso, Índia, Paquistão, Nepal e Bangladesh tem hoje em comum um sistema de cotas a nível local e nacional (para os três últimos países) que estrutura as condições de acesso das mulheres aos mandatos eletivos, o que possibilita debates comparativos sobre a participação política das mulheres. Nesses países, a (re) implementação das cotas foi feita em nome do imperativo democrático que constitui na participação e na representação política das mulheres. No entanto, o entusiasmo frente a feminização da vida política dura muito pouco tempo pelo fato que as representantes eleitas devam seus postos de trabalho ao seu marido ou a seu pai, dos quais elas representam os interesses, mais do que aqueles das mulheres ou do povo.

Existe, portanto, um triângulo de relações complexas entre a participação política das mulheres, o papel da família na política e a "boa democracia" com esse paradigma normativo. Este triângulo não é novo visto que a construção e a separação discursiva entre a esfera dita privada ou familiar e uma esfera política e pública foi uma justificativa dada para a exclusão política das mulheres nos sistemas políticos liberais e democráticos: porque elas estão prioritariamente ligadas à esfera familiar, marcada pelos afetos e fundada na diferenciação de indivíduos, as mulheres seriam incapazes de se comportarem como boas cidadãs imparciais ${ }^{6}$. Da mesma forma, segundo Claude Patriat, a interferência do político e do familiar somente é transgressiva "se alguém admitir como intangível a divisão entre o "público" e o "privado"7. Sem dívida, não é uma coincidência o fato das mulheres (e as domésticas, aquelas ligadas à esfera familiar) terem sido excluídas do corpo eleitoral durante a Revolução Francesa, no momento onde foram impostas as restrições eleitorais de vários membros de uma mesma família dentro das municipalidades ${ }^{8}$. Seja qual for a interpretação dada a exclusão política das mulheres, a ligação delas com à família e as relações de

\footnotetext{
${ }^{6}$ PATEMAN, Carole. 0 contrato sexual. Cambridge: Polity Press, 1988

PISSIER, Evelyne e VARIKAS, Eleni. "Da invisibilidade do gênero na teoria política: o debate Locke / Astell". In: BARD, Christine; BAUDELOT, Christian e MOSSUZ-LAVEAU, Janine (orgs). Quando as mulheres se envolvem: gênero e poder. Paris: La Martinière, 2004, p. 64-79.

7 PATRIAT, Claude. "Perspectiva amazona: de onde se fala sobre pessoas que são natural e legitimamente elegíveis por herança". In: PATRIT, Claude e PARODI, Jean-Luc (orgs). A hereditariedade na política. Paris: Economica, 1992, p. 1.

8 FORTUNET, Françoise. "A proibição parental. Da inelegibilidade devido ao parentesco: o exemplo das eleições municipais no período revolucionário". In: PATRIAT, Claude e PARODI, Jean-Luc (orgs). A hereditariedade na política, op. cit., p. 37-44.
} 
dependência que desempenham tem um papel fundamental ${ }^{9}$. Na Ásia Meridional, a constituição do "privado" e do "público" e dos valores atribuídos a estas áreas foram profundamente afetadas pela colonização britânica, e as questões familiares e conjugais desempenharam um papel estruturante na política nacionalista ${ }^{10}$. De acordo com Partha Chatterjee, o lar e a vida familiar constituem o local a partir do qual foi construída a resistência cultural e política à colonização, o que deu às mulheres um papel político importante, mas subordinado aquele dos homens que dominaram os grandes movimentos nacionalistas ${ }^{11}$. Se a maneira como o "público" e o "privado" são construídos e articulados nos Estadosindependentes está enraizada nesta história colonial, o ideal de separação entre interesses públicos e interesses privados são, no entanto, operacionais, como testemunham os discursos críticos sobre o nepotismo e os herdeiros políticos, que particularmente visam os Gandhi (na Índia) e a família BhuttoZardari (no Paquistão) quando das últimas eleições gerais nestes dois países ${ }^{12}$.

As herdeiras, portanto, contradizem tanto a lógica democrática igualitária como a lógica familiar desigual. As situações nas quais elas "herdam" o poder político é, portanto, particularmente interessantes para se analisar porque elas nos levam a considerar a família sendo uma instituição marcada pelo poder e pelas desigualdades. As herdeiras levantam a questão da natureza do "poder" que é transmitido aos indivíduos das famílias políticas e da relação entre as hierarquias familiares e as hierarquias políticas. Duas perguntas parecem particularmente importantes; primeira: as mulheres herdam por serem mulheres ou apesar de seu sexo? Mais especificamente, existem contextos familiares e políticos que são estruturalmente mais favoráveis às mulheres? Segunda questão: em que medida a família constitui um recurso para as mulheres e qual é o custo desse recurso?

Do ponto de vista metodológico, duas abordagens podem ser utilizadas para esboçar as respostas a estas perguntas. Para C. Patriat, é pela análise local (circunscrição, cidade, distrito) que podemos capturar

\footnotetext{
9 J. Scott insiste na exclusão das mulheres do corpo universal e de cidadão, enquanto Anne Verjus enfatiza sua integração diferenciada através da família, a unidade básica do voto na época da Revolução.

SCOTT, J. W. "Feministas francesas e os direitos do 'Homem'": Declarações de Olympus de Gouges". In: Workshop de História, 28, 1989, p. 1-21.

VERJUS, Anne. 0 censo da família: mulheres e voto (1789-1848). Paris: Belin, 2002.

Nota tradutora: Declarações de Olympe de Gouges é a Declaração dos Direitos da Mulher e da Cidadã, um texto jurídico produzido em 1791, exigindo status de completa assimilação jurídica, política e social das mulheres, escrito por Marie Gouze conhecida por Olympe de Gouges sobre o modelo da Declaração dos Direitos do Homem e do Cidadão que fora proclamada em 27 agosto de 1789, mas não contemplava às mulheres.
}

10 SARKAR, Tanika. Esposa hindu, nação hindu: comunidade, religião e nacionalismo cultural. Bloomington: Indiana University Press, 2001

11 CHATTERJEe, Partha. A Resolução Nacionalista e a questão das mulheres. Calcutá: Centro de Estudos em Ciências Sociais, Ocasional Paper № 94, 1987.

12 Consultar "As pessoas rejeitaram a regra dinástica: BJP". In: O Hindu, 16 de maio de 2014. Disponível em http://indianexpress.com/article/india/politics/people-have-rejected-dynastic-rule-bjp/.

REHMAN, Asha'ar. "Herdeiros de todos os reis aparentes". In: Dawn, 27 de abril de 2013. 
melhor os fenômenos da herança política ${ }^{13}$. Neste caso, a falha desta abordagem é que as herdeiras permanecem raras, sendo uma abordagem excessivamente limitada pelo escopo da análise de um ou dois casos. A outra opção, que é a adotada aqui, consiste em trabalhar em uma escala maior para construir tipos ideais. O risco dessa metodologia é o de se fazer generalizações precipitadas. Este artigo explora, em primeiro lugar, dados sobre as redes de parentesco de cerca de 450 parlamentares eleitos entre 1947 e 2014 na Índia, e esses dados foram cruzados com entrevistas qualitativas realizadas com profissionais da política ${ }^{14}$. O cruzamento dos dados quantitativos e qualitativos permitiu construir um quadro mais preciso do papel do parentesco no acesso das mulheres aos mandatos parlamentares, e assim melhor compreender o papel do parentesco na transmissão de mandatos eletivos.

Este estudo está estruturado em três partes. Retornaremos primeiro ao o papel da família no sistema político indiano, a fim de avaliar o lugar das mulheres. Em seguida, analisaremos as configurações familiares que as mulheres herdam. Finalmente, mostraremos a ambivalência do recurso familiar para as mulheres.

\section{Família e política na Índia: quadro metodológico e empírico}

A importância dos laços familiares e do nepotismo ocupa um lugar esteriotipado tanto nos discursos científicos ${ }^{15}$ quanto nos jornalísticos que politizam ou profanam, sobre a vida política do sul asiático. Como muitos dos estereótipos, o da "família política" é ao mesmo tempo inevitável e difícil de manipular. No sentido amplo da palavra, o conceito de parentesco pode se referir tanto a família nuclear ou extensa, quanto a casta ou tribo. No contexto deste artigo, nos limitaremos a um sentido limitado de família, reduzido a laços de parentesco com base na pertença a uma linhagem comum, que pode ser pelo nascimento, adoção ou casamento. Mesmo com esta definição relativamente estreita de parentesco, sua

\footnotetext{
13 PATRIAT, C. "Perspectiva amazona: de onde se fala sobre pessoas que são natural e legitimamente elegíveis por herança". op.cit., p. 13

14 Entre 2009 e 2013, realizamos cerca de 30 entrevistas semi-estruturadas, em inglês ou hindi, com parlamentares e antigos parlamentares indianos de ambos os sexos. Os extratos da entrevista foram traduzidos por nós, numerados, e o gênero do (a) eleito(a) foi especificado. Os dados quantitativos foram coletados pela primeira vez como parte de uma tese (V. Dutoya, A Representação das mulheres nos Parlamentos da Índia e do Paquistão, op. cit.), depois no âmbito do EECURI (Explicando as mudanças eleitorais na Índia Urbana e Rural), agrupando pesquisadores do Centro de Pesquisas Internacionais (CERI) e do Centro de Dados Sócio-políticos (CDSP) de Ciências Políticas, do Instituto King's India (King's College London), da London School of Economics (LSE), do Commonwealth Institute (Londres), da Universidade Jawaharlal Nehru (JNU, Nova Deli), do Centro para o Estudo das Sociedades em Desenvolvimento (Delhi), do Centro de Cidadania e Democracia do Janaagraha (Bangalore) e da Universidade de Ambedkar de Lucknow.
}

${ }^{15}$ CHANDRA, K. (org). Dinastias democráticas: estado, partido e família na política indiana contemporânea, op. cit. JAFFRELOT, Christophe. "Índia: democracia dinástica ou democracia de linhagem?" In: Crítica internacional, 33, 2006, p. 135152.

MUFTI, Mariam. "Política dinástica no sul da Ásia". In: South Asian Journal, 20, 2008, p. 9-19.

A revista indiana SEMINAR dedicou um número $(622,2011)$ às dinastias política - DINASTIA: um simpósio sobre linhagem e laços familiares na política subcontinental. Disponível em (http://india-seminar.com/2011/622.htm). Acesso em 13 de julho de 2015. 
importância não é tão óbvia para se destacar. No caso das parlamentares indianas, fomos confrontados com duas dificuldades principais. De início, em termos práticos, os laços familiares das eleitas não são fáceis de estabelecer, especialmente para os períodos mais antigos. Depois, quando estes laços são estabelecidos, a questão que permanece é o da interpretação do papel desempenhado pelas redes de parentesco. Esta questão é ainda mais importante quando se trata de mulheres, para quem o fato de ter um parente na política é geralmente considerado prova irrefutável de que elas se beneficiaram do seu apoio para entrar na política. É importante distinguir entre o fato de ter um ou mais parentes na política e o fato de ter essa rede familiar como um recurso principal na competição política. Nesse sentido, a distinção proposta por Christophe Jaffrelot entre a política "dinástica" e " de linhagem" é útil porque torna possível considerar o parentesco como um recurso entre outros: se a linhagem é, sem dúvida, um trunfo na Índia, os herdeiros devem ao menos "habituar-se ao nome"16.

Neste artigo, falaremos sobre a transmissão familiar do poder político e da "família política" para se referir às diferentes configurações em que vários membros de uma mesma família extensa participam da política eleitora $\left.\right|^{17}$. As representantes eleitas que se beneficiaram deste tipo de transmissão de mandatos para entrarem na política serão consideradas como tendo passado pela "rede familiar" ou, por simplicação, como as "herdeiras". O fato para um ou uma eleito/a de ter sido precedido/a na vida política por um ou mais membros de sua família não é um indicador suficiente da existência de uma rede familiar. No entanto, na medida em que, para as eleitas das décadas de 1950 a 1980, muitas vezes era difícil coletar os dados para determinar com precisão sua via de acesso na política, é útil identificar as mulheres eleitas que possuem parentes políticos, pois isso pode dar uma indicação do papel da rede familiar.

De acordo com Kanchan Chandra e Wamiq Umaira, cujos trabalhos se concentram na décima quinta legislatura do Lok Sabha (Assembleia Nacional) da Índia (2009-2015), quase 34\% dos deputados (as) têm membros da família que também estão investidos na política ${ }^{18}$. Estes números estão próximos dos compilados pelo jornalista Patrick French em seu banco de dados em $2010^{19}$. Segundo ele, um pouco menos do que um terço dos 545 deputados(as) tiveram conexões familiares que facilitaram sua eleição. Não há dados tão precisos para outros países da Ásia Meridional, mas diferentes trabalhos jornalísticos e

\footnotetext{
${ }^{16}$ JAFFRELOT, C. "Índia: democracia dinástica ou democracia de linhagem?", op.cit.

17 "Política Eleitoral" significa ser um candidato (e ainda mais eleito/a) nas eleições locais, estaduais ou nacionais, ou ter uma posição dentro de um partido envolvido na competição eleitoral. São também consideradas algumas posições não eletivas, como ser nomeado/a como presidente/a em uma assembleia.

18 CHANDRA, Kanchan e UMAIRA, Wamiq. "Dinastias democráticas da Índia". In: SEMINAR, 622, 2011 (http://indiaseminar.com / 2011/622 / 622 kanchan \& wamiq.htm) (acessado em 15 de junho de 2015).

$19 \mathrm{O}$ banco de dados está disponível em http://www.theindiasite.com/family-politics. R. Carlevan dá números semelhantes para as deputadas do norte da Índia na década de 2000. CARVELAN, R. «Esposas e viúvas, matriarcas e mestras: classificando dinastias femininas na Índia contemporânea do Norte (1952-2014)", comunicação para a conferência EECURI, CERI, Paris, 22 de junho de 2015.
} 
relatórios sugerem tendências similares ${ }^{20}$. As mulheres representam neste período $10 \%$ dos deputados indianos, os homens são os principais beneficiários das transmissões familiares do poder político (mais de 70\% dos herdeiros de acordo com P. French). Entretanto, considerando o número total de mulheres eleitas, parece que a proporção de mulheres que se beneficiaram desse tipo de transmissão de recursos políticos é singularmente mais elevada do que os homens. Assim, de acordo com o banco de dados de P. French, $76,2 \%$ das mulheres eleitas em 2009 contra $24,8 \%$ dos homens devem suas cadeiras as suas conexões familiares. Como parte do nosso trabalho, fomos capazes de atestar que quase $61 \%$ das deputadas eleitas entre 2004 e 2009 eram herdeiras ${ }^{21}$. Como resultado, a figura da herdeira é frequentemente invocada na análise de participação política das mulheres indianas, particularmente para explicar que existem mulheres nas posições mais altas desde a década de 1960. A hereditariedade é apresentada como a chave do paradoxo que seria o acesso das mulheres as posições políticas elevadas, embora frequentemente elas sofram com desigualdades importantes em termos de acesso à educação, à saúde e aos recursos econômicos. De acordo com essa lógica, se houve uma mulher à frente do Estado indiano em 1966 (e em 1988 no Paquistão), não é porque esses países estavam mais avançados do que outros em termos de igualdade de gênero, mas ao contrário, por serem mais arcaicos a política nesses locais é ainda patrimonial e pouca institucionalizada ${ }^{22}$.

As herdeiras estão, portanto, na encruzilhada de dois grandes problemas da vida política na Índia (e no sul da Ásia): os fenômenos de transmissão intrafamiliar do poder e o acesso das mulheres aos mandatos eleitorais. Assim, seu estudo possibilita esclarecer cada um dos dois fenômenos, mas também de compreender a sua interligação.

\section{Quando as mulheres herdam: gênero, parentesco e poder político}

As mulheres constituem a minoria dos herdeiros, mas as herdeiras políticas são a maioria entre as mulheres parlamentares. Como resultado, é legítimo questionar sobre a especificidade das heranças femininas. Para fazer isso, é útil demonstrar os casos típicos que uma mulher herda, afim de poder avaliar sua especificidade.

\footnotetext{
${ }^{20}$ O número de SEMINAR (citado) sobre dinastias políticas inclui artigos sobre diferentes países da Ásia Meridional.

${ }^{21}$ Amrita Basu apresenta valores próximos: 58\% dos herdeiros eleitos para Lok Sabha em 2004, 69\% em 2009 e $48 \%$ em 2014. In: BASU, A. "Mulheres, dinastias e democracia na Índia", op.cit., p. 137.

22 KATSENSTEIN, Mary. "Rumo à igualdade? Causa e consequência da proeminência política das mulheres na Índia". In: Asian Survey, 18 (5), 1978, p. 482. JAHAN, Rounaq. "Mulheres na política do Sul da Ásia". In: Terceiro Mundo Quaterly, 9 (3), 1987, p. 854. RITCHER, Linda. "Explorando teorias da liderança feminina no sul e no sudeste Ásia". In: Pacific Affairs, 63 (4), 1990-91, p. 528.
} 


\section{Em que contextos as mulheres herdam um mandato?}

É certo que devemos olhar para o contexto familiar, isto é, para as relações de parentesco colocadas em jogo pela transmissão, mas também devemos prestar atenção ao contexto político de herança e aos laços entre essas duas dimensões. Embora de maneira caricatural, uma abordagem tipológica permite distinguir tipos ideais úteis para a análise. Em primeiro lugar, é importante distinguir que o fenômeno familiar e a linhagem de transmissão envolvem apenas dois tipos de indivíduos. No primeiro caso, há pelo menos três indivíduos da mesma família envolvidos e se ajudando uns aos outros na política ao longo de várias gerações. É difícil identificar se um laço foi mobilizado de forma mais específica, mas podemos especificar se o eleito nasceu ou se casou em uma família política (a combinação de ambos é bem comum). Então, essas famílias podem ser "reais", isto é, com origens nos antigos estados principescos do subcontinente, ou podem ser "plebeias". No segundo caso, o detentor do poder político o transmite diretamente para um membro de sua família, que o exercita durante sua vida ou após a morte dele. Convém sempre distinguir as situações de parentesco (pai para filho, mais raramente avô para o neto ou tio/tia para sobrinho/sobrinha) dos laços maritais.

O Quadro 1 destina-se principalmente a dar as ordens de grandeza. Ele identifica os eleitos que possuem um ou vários membros da sua família na política. Nem sempre temos elementos para certificar se foi essa relação de parentesco que permitiu a mulher eleita de entrar na política, principalmente para o início do período. No entanto, quando dispomos de tais elementos (entrevistas, (auto) biografias detalhadas, recortes de jornais), geralmente observamos uma forte concordância entre o fato de ter conexões familiares e a utilização dessas conexões como via de acesso ao parlamento.

\section{Quadro 1 - Conexões familiares das parlamentares indianas (1952-2010)23}

\begin{tabular}{|c|c|c|c|c|}
\hline & \multicolumn{2}{|c|}{ CÂMARA ALTA } & \multicolumn{2}{|c|}{ CÂMARA BAIXA } \\
\hline Pai - Avó & 26 & $8,4 \%$ & 15 & $8,5 \%$ \\
\hline Mãe & 1 & $0,3 \%$ & 0 & $0,0 \%$ \\
\hline Tio & 1 & $0,3 \%$ & 1 & $0,6 \%$ \\
\hline Irmão/irmã - primo/prima & 6 & $1,9 \%$ & 1 & $0,6 \%$ \\
\hline Esposo & 70 & $22,6 \%$ & 30 & $16,9 \%$ \\
\hline Sogro & 3 & $1,0 \%$ & 0 & $0,0 \%$ \\
\hline \multicolumn{5}{|c|}{ FAMÍLIA } \\
\hline Família real & 27 & $8,7 \%$ & 9 & $5,1 \%$ \\
\hline Outra família política & 36 & $11,6 \%$ & 10 & $5,6 \%$ \\
\hline \multicolumn{5}{|c|}{ OUTROS } \\
\hline Outro tipo de conexão & 8 & $2,6 \%$ & 5 & $2,8 \%$ \\
\hline Descendente & 1 & $0,3 \%$ & 4 & $2,3 \%$ \\
\hline Sem conexão conhecida & 131 & $42,3 \%$ & 102 & $57,6 \%$ \\
\hline TOTAL EFETIVOS & 310 & & 177 & \\
\hline
\end{tabular}

Fonte: dados da autora

\footnotetext{
${ }^{23}$ Algumas deputadas foram eleitas em ambas as câmaras, então elas aparecem duas vezes no quadro. Por outro lado, dentro de cada câmara, cada mulher é contada apenas uma vez, independentemente do número de mandatos.
} 
Uma primeira observação é o domínio das transmissões entre cônjuges, seguido por transmissões familiares, depois por filiação. No caso das transmissões entre cônjuges, existem duas configurações principais: aquela em que um homem ainda vivo beneficia sua esposa com o capital político que ele adquiriu anteriormente, e aquela onde uma viúva herda o capital político após a morte de seu marido. Maneka e Sonia Gandhi são sem dúvidas as viúvas mais conhecidas, mas elas não pegaram diretamente a circunscrição eleitoral de seus maridos, como é o caso de Putul Kumari, deputada eleita do Bihar em uma eleição parcial após a morte de seu marido em 2010. Como acontece regularmente neste tipo de situação, ela não tinha opositores. Mais raramente, uma mulher é eleita quando seu marido não pode ou não quer ser candidato ele próprio porque ele quer se dedicar a outras tarefas, ou porque está inelegível, particularmente envolvido em negócios de corrupção. Da mesma maneira, uma morte ou inelegibilidade são os motivos mais frequentes da causa da passagem de um mandato de seu pai para a sua filha. No entanto, enquanto as viúvas às vezes, apenas fazem um trabalho temporário, as filhas muitas vezes conservam o posto que elas conseguiram obter de maneira quase acidental. Em outros casos, não é uma sucessão, mas uma extensão da rede familiar existente. Por exemplo, a sobrinha de Atal Vajpayee, primeiro-ministro da Índia entre 1998 e 2004, foi eleita para o Parlamento em 2004.

Quanto às configurações em que toda a família engajada na política está envolvida, há uma diferença notável (mas não sistemática) entre famílias políticas reais e as famílias "plebeias". No primeiro caso, a família está acima de tudo anexada a um território específico, o que corresponde a região onde a família historicamente tinha poder político e geralmente conserva propriedades significativas. No segundo caso, se o relacionamento com o poder pode ser territorializado, existem famílias que são antes de mais nada repositórias de um patrimônio político, muitas vezes vinculadas a um partido. $\mathrm{O}$ arquétipo da família política na Ásia Meridional é a família Nehru-Gandhi que, de Motilal Nehru, nascido em 1861, a Rahul Gandhi, nascido em 1970, dominou a vida política indiana ao longo de cinco gerações. Aqueles ou aquelas que nasceram ou se casaram nesta família compartilham um grande capital político, assumindo a forma de uma socialização política precoce (para aquelas que nascem na família), uma rede social alargada e um nome de prestígio. Este nome sobretudo evoluiu quando Indira, filha de Jawaharlal Nehru, tomou o nome de seu marido, Feroze Gandhi. Ela se tornou primeira-ministra em 1966, dois anos após a morte de seu pai ${ }^{24}$. Esta família está intrinsecamente ligada ao Congresso, apesar das dissidências pontuais ou duráveis.

\footnotetext{
24 Nota tradutora: Jawaharlal Nehru, também conhecido como Pandit Nehru ou Pandita Nehru foi o primeiro primeiro-ministro da Índia de 1947 até 1964. Pai de Indira Gandhi.

Indira Priyadarshini Gandhi foi primeira-ministra da Índia entre 1966 e 1977 e entre 1980 e 1984 . Indira Gandhi não possui nenhum parentesco com Mahatma Gandhi. Esposa de Feroze Gandhi.

Feroze Gandhi tornou-se um membro do parlamento provincial (1950-1952), e mais tarde um membro do Lok Sabha, a Câmara Baixa do parlamento da Índia até o ano de sua morte em 1960. Com Indira teve dois filhos: Rajiv Gandhi e Sanjay Gandhi.
} 
Em 1977, Vijaya Lakshmi Pandit fez campanha contra sua sobrinha Indira, porque ela desaprovava o estado de emergência estabelecido em $1975^{25}$. Maneka, esposa de Sanjay, um dos filhos de Indira Gandhi, se juntou ao Partido do Povo Indiano (Bharatiya Janata Party - BJP) após a morte de seu marido, e depois foi seguida por seu filho, Varun. Isso não impede a família de ter bastiões claramente identificados, mas esses bastiões são geralmente definidos de forma bastante ampla, na escala da região mais do que da localidade. Assim, no estado do norte de Uttar Pradesh, o Partido Samajwadi está fundamentalmente ligado a Mulayam Singh Yadav, que gradualmente colocou homens de sua família em diferentes posições políticas eletivas da região, e a sua nora, Dimple, eleita, sem oposição, em uma eleição parcial em 2012, para a cadeira que seu marido ${ }^{26}$ acabara de desocupar. Encontramos aqui, certamente, uma lógica de bastião, mas que se estende amplamente, já que Indira Gandhi foi eleita em diferentes estados, o que destaca sua influência nacional. Por outro lado, no que diz respeito às famílias reais, observamos menor mobilidade de implantação (exceto pelo casamento para mulheres), mas uma alta volatilidade partidária.

O caso das famílias reais mostra a complexa interação entre filiação e conjugalidade. Se, no caso das chamadas transmissões simples, os dados sugerem que as mulheres se beneficiam mais do patrimônio político de seus maridos do que dos seus pais, nas famílias políticas, os laços de filiação parecem mais favoráveis para a transmissão política. Na verdade, das 36 deputadas pertencentes a uma família política (real ou não), 16 nasceram nessa família e 12 se casaram com membros dessa família, as demais acumulam nascimento e casamento. Essa acumulação é quase sistemática em famílias (exceto, é claro, para aquelas que não são casadas), mas as mulheres são geralmente eleitas dentro da circunscrição de seus maridos. Então, Vijayaraje Scindia ${ }^{27}$ em Madhya Pradesh e Gayatri Devi em Jaipur foram ambas eleitas nos feudos de seus maridos, os marajás que nunca foram candidatos à deputação ${ }^{28}$. Quanto a Vasundhara Raje, filha de Vijayaraje, nascida na poderosa dinastia Scindia, em Madhya Pradesh, e filha de uma influente figura do

Sonia Gandhi, presidente do Partido do Congresso, é viúva do ex-primeiro-ministro Rajiv Gandhi e nora da também ex-primeiraministra Indira Gandhi.

Maneka Gandhi ganhou a primeira eleição para deputada em 1989. Tem sido ministra em quatro governos. É viúva de Sanjay Gandhi e nora de Indira Gandhi. Sanjay era político e esperava-se ser o sucessor da mãe, Indira Gandhi como chefe do Congresso Nacional da Índia, mas após sua morte precoce em um acidente de avião, seu irmão mais velho, Rajiv, se tornou o herdeiro político de sua mãe e sucedeu-a como primeiro-ministro da Índia depois da morte dela. A viúva de Sanjay, Maneka Gandhi e o filho Varun Gandhi, são líderes políticos no BJP .

25 PANDIT, Vijaya Lakshmi. O alcance da felicidade. Nova York: Crown Publisher, 1979, p. 13.

26 Nota tradutora: Akhilesh Yadav é o marido de Dimple.

27 Sobre a família Scindia, ver CARLEVAN, R. "Dinastias políticas da Índia Central", tese de mestrado em História do IEP de Paris, 2011, p. 100-122, e JAFFRELOT, C. "O que é democracia principesca? O caso das Scindias". In: SEMINAR, 622, 2011 (http://indiaseminar.com/cd8899/cd frame8899.html) (acessado em 15 de junho de 2016).

${ }^{28}$ Após a eleição triunfal de Gayatri Devi como deputada de Jaipur em 1962, bem como alguns de seus filhos, o Maharaja foi eleito senador (por método de votação indireta). Ele mesmo nunca pediu os votos de seus antigos súditos. Consultar DEVI, Gayatri e RAU, Shantha Rama. Lembranças de uma princesa: as memórias de Maharani de Jaipur. Londres: Weidenfeld e Nicolson, 1976, p. 266. 
BJP, ela foi viver em Rajasthan após seu casamento com o herdeiro de uma família real. Ela rapidamente se separou do marido, mas foi eleita depois disso na circunscrição eleitoral que corresponde ao seu antigo estado principesco, depois em um outro eleitorado, sempre em Rajasthan. A socialização política que teve perto de sua mãe ela também encontrou no território de dominação da família de seu marido ${ }^{29}$.

No caso da família Scindia, pode-se observar uma implantação estratégica (mas nem sempre combinada) da família na cena política regional e nacional. No entanto, as mulheres frequentemente acessam aos mandatos em contextos políticos menos planejados. Na verdade, há uma situação recorrente qualquer que seja o contexto familiar, que é aquele da crise, devido à morte inesperada no curso de um mandato. $\mathrm{O}$ vazio político gerado por esta morte parece ser favorável às mulheres, ou pelo menos as mulheres parecem ser menos desfavorecidas do que elas geralmente são na competição política. Em vista desta vantagem relativa que tem as mulheres em alguns contextos, é importante se colocar a questão do tipo da transmissão familiar dos mandatos e das formas específicas que teriam (ou não) as mulheres para se beneficiarem.

\section{Transmissões femininas, masculinas ou de gênero?}

A filha obediente, a princesa e a esposa/viúva constituem três tipos ideais de herdeira, que não são mutuamente exclusivas. Para determinar a maneira como esses tipos ideais são gerados, é útil colocar em perspectiva os dados relativos às mulheres com aqueles referentes aos homens. A este respeito, o banco de dados coletado por Patrick French em 2010 possibilita evidenciar as especificidades da transmissão do poder político para as mulheres.

\section{Quadro 2 - Conexões familiares dos deputados indianos (2009-2014)}

\begin{tabular}{lccccc}
\hline \multicolumn{1}{c}{ TIPO DE LIGAÇÃO DE PARENTESCO } & \multicolumn{2}{c}{ MULHERES } & \multicolumn{2}{c}{ HOMENS } & TOTAL \\
\hline Cônjuge & $12(4)$ & $20,3 \%$ & 0 & $0 \%$ & 12 \\
\hline Cônjuge falecido & 4 & $6,8 \%$ & 0 & $0 \%$ & 4 \\
\hline Pai - avô & 12 & $20,3 \%$ & 69 & $14,2 \%$ & 81 \\
\hline Tio - tio-avô & 0 & $0 \%$ & 7 & $1,4 \%$ & 7 \\
\hline Irmão (a) - primo (a) & 2 & $3,4 \%$ & 11 & $2,3 \%$ & 13 \\
\hline Sogro / sogra & 1 & $1,7 \%$ & 5 & $1 \%$ & 6 \\
\hline Cunhado & 0 & $0 \%$ & 1 & $0,2 \%$ & 1 \\
\hline Outra família política & 10 & $16,9 \%$ & 21 & $4,3 \%$ & 31 \\
\hline Família Real & 4 & $6,8 \%$ & 7 & $1,4 \%$ & 11 \\
\hline Sem conexão conhecida & 14 & $23,7 \%$ & 365 & $75,1 \%$ & 379 \\
\hline TOTAL DE EFETIVOS & 59 & & 486 & & 545 \\
\hline
\end{tabular}

Fonte: Patrick French, http://www.theindiasite.com/family-politics.

29 "Destinos reais: Vasundhara Raje Scindia". In: Times of India, 21 de dezembro de 2003. 
Em primeiro lugar, parece que a conjugalidade é mobilizada de maneira diferente por homens e por mulheres. Na política, os laços matrimoniais podem ser usados de três maneiras: pode-se beneficiar diretamente do capital político do cônjuge, pode-se beneficiar do capital político de outro membro da nova família, e por fim, podemos nos casar em uma família política e nela ser integrado. Os dados de que dispomos sugerem que muitos poucos maridos de mulheres políticas herdam diretamente delas, por outro lado, eles podem usar o capital político da família de sua esposa. Inversamente, muitas mulheres se beneficiam do capital político de seus maridos, ou mesmo do da sua família conjugal, mas muitas poucas herdam direta e exclusivamente do sogro. De fato, a mulher pode ser facilmente integrada no seio da família política onde os cargos são muitos, e servir de suplente para o marido, sendo que seria surpreendente um homem transmitir sua circunscrição para a sua nora e não para seu filho. No entanto, um genro pode ser considerado como um herdeiro tão válido quanto uma filha.

A diferença entre homens e mulheres é particularmente clara sobre a viuvez. O "véu das viúvas"30 funciona amplamente na Ásia Meridional e constitui uma rota de acesso tipicamente feminina. Então, quase um terço das parlamentares cujo cônjuge já esteve na política (Quadro 1) são, de fato, viúvas. Por outro lado, há poucos viúvos (ou indivíduos reivindicando esse status) no parlamento indiano. Assim, em meados dos anos $2000,21 \%$ das deputadas indianas eram viúvas, contra menos de $2 \%$ dos membros eleitos. Isto é parcialmente explicado pelo fato de que o marido é frequentemente o mais velho do casal, e um novo casamento é mais comum entre os homens. Não há nenhum exemplo de um homem ocupando a cadeira que era de sua esposa após a morte dela, sendo depois substituído por uma pessoa considerada mais competente. Do outro lado da fronteira, somos tentados a falar do caso de Asif Ali Zardari, viúvo de Benazir Bhutto, que se tornou presidente da República (e co-presidente do partido) após o assassinato de sua esposa. Zardari vem de uma família engajada na vida política, na qual ele participava quando sua esposa era viva e não mostrou nenhuma inclinação de se retirar depois de o exercer interinamente.

Homens e mulheres parecem mais iguais em relação à filiação, mesmo se os "filhos de" são mais numerosos do que as "filhas de". Da mesma forma, e embora isso seja mais raro, as mulheres também podem transmitir seu patrimônio familiar para seus filhos, como no caso da família Scindia, já mencionada. A família Nehru-Gandhi, que se estende sobre várias gerações, torna possível observar os mecanismos de sucessão. A este respeito, não parece haver nenhuma regra de sucessão fixa, seja ela baseada na primogenitura ou no sexo. Jawaharlal Nehru era o filho mais velho (e filho único), mas ele não é apenas o herdeiro de seu pai, porque de muitas maneiras, foi ele que deu a dinastia familiar toda sua dimensão. Além disso, suas irmãs também se envolveram na política. Porém nunca houve uma competição real entre irmãos e irmãs; Indira era filha única, e teve dois filhos; o mais velho somente se engajou depois da morte prematura de seu irmão caçula, o herdeiro designado. Por outro lado, na situação atual, somente Rahul, o

${ }^{30}$ SINEAU, Mariette. Mulheres na política. Paris: Economica, 1988, p. 54 
neto de Indira, se envolveu na política eleitoral ao lado de sua mãe Sonia (até o fiasco de maio de $2014^{31}$ ). Sua irmã mais nova Priyanka no entanto, participa em todas as campanhas eleitorais como gerente de campanha. Mais uma vez, a comparação com a família Bhutto é interessante. Benazir Bhutto teve dois irmãos mais novos que mostraram sinais de compromisso político. Ambos morreram em circunstâncias suspeitas, especialmente Murtaza, morto em um choque com a polícia em 1996, enquanto sua irmã era a primeira-ministra. Ela e seu marido eram suspeitos de estarem envolvidos neste assassinato. Parece que houve um conflito entre o direito de nascimento de Benazir e o da masculinidade do irmão. Por outro lado, há menos debate sobre Bilawal, seu filho mais velho, que é o herdeiro designado, embora seu compromisso permaneça limitado.

Uma diferença notável entre os "filhos de" as "filhas de" é que aquelas herdeiras de seu pai são frequentemente solteiras. Um pouco mais de $25 \%$ das deputadas que se beneficiaram do patrimônio político de seu pai nunca haviam se casado quando do momento da sua primeira eleição. Estatísticas semelhantes não estão disponíveis para os homens, mas na medida em que, de acordo com as análises feitas de três legislaturas, entre $2 \%$ e $8 \%$ delas nunca foram casadas ${ }^{32}$, sendo pouco provável que se atinja tal taxa. Esta especificidade provavelmente é explicada pelo casamento que geralmente é patrilocal e depende da integração da nora na família de seu marido. Além disso, as mulheres solteiras não têm filhos (oficialmente). Logo, mesmo que a realidade seja mais complexa, a ideia segundo a qual as mulheres devem se ocupar com prioridade dos seus filhos é muitas vezes mencionada como um obstáculo pelas mulheres parlamentares ${ }^{33}$. Então, uma deputada da Shiv Sena foi escolhida por seu pai, que tinha apenas filhas, porque suas irmãs mais velhas já estavam casadas (entrevista 63, 2011).

Neste último caso, a filha foi escolhida por "falta de melhor". Os filhos são muitas vezes as prioridades e, quando as filhas se envolvem com a vida política, elas costumam fazer mais do que seus irmãos, e não em seu lugar. Uma congressista, originária de uma família real, explicou-nos que após anos de engajamento político sempre houve gente considerando surpreendente que ela fizesse política, uma ocupação que seria mais adequada aos homens (entrevista 66, 2011). Da mesma forma, quando perguntamos aos nossos(as) entrevistados(as) se seus filhos pensavam em se juntar à política, eles(as) responderam com frequência mencionando primeiro (ou mesmo exclusivamente) os filhos. Em algumas populações tribais, no entanto, as meninas são as herdeiras habituais. Agatha Sangma, deputada eleita em

\footnotetext{
31 Nota da tradutora: Em 2014, Rahul Gandhi foi o principal candidato governista ao cargo de primeiro-ministro nas eleições gerais, mas perdeu o pleito para Narendra Modi da oposição.

Consultar Sonia Gandhi se opõe à candidatura do filho para premiê da Índia. Disponível em http://g1.globo.com/mundo/noticia/2014/01/sonia-gandhi-se-opoe-candidatura-do-filho-para-premie-da-india.html. Acesso 25.outubro.2017.

32 São a Sexta, Oitava e Décima Quarta Legislaturas. Consultar DUTOYA, V. A representação das mulheres nos Parlamentos da Índia e do Paquistão, op. cit., p. 225 e 391.

33 Ibid., p. 433.
} 
2008, com a idade de 28 anos, é a filha mais nova, a herdeira do seu clã, o que explica por que seu pai a escolheu para o lugar de deputado que ele liberou (entrevista 70, 2011).

Sem dúvidas, uma filha herda na frente de seus irmãos por razões de temperamento e afinidades individuais. No entanto, excetuando o caso de Agatha Sangma, é difícil encontrar situações em que, estruturalmente, as mulheres sejam favorecidas na transmissão do poder político. Além disso, se elas podem ser herdeiras, as mulheres raramente transmitem seu compromisso político quando ele lhe é próprio (isto é, fora das famílias políticas). Como evidenciado pelo caso da dinastia feminina fundada por Ammu Swaminadhan (1894-1978) 34. Já na década de 1920, esta última se engajou no Congresso e dentro do movimento feminino. Ela era então a representante da província de Madras na Assembleia Constituinte, como deputada. Suas duas filhas (mas não seus filhos) se envolveram na política. A mais velha, Lakshmi, se juntou durante a Segunda Guerra Mundial ao Exército Nacional Indiano de Subhas Chandra Bose e a sua filha mais velha, Subhashini ${ }^{35}$, é uma ativista comunista e feminista que foi eleita deputada na década de 1980. Mrilani, a filha mais nova, é uma dançarina reconhecida e casada na família Sarabhai, uma família de industriais da área têxtil de Gujarat. Nesta família também, as mulheres estavam envolvidas tanto com o nacionalismo, como com o sindicalismo. A filha de Mrilani, Mallika, é dançarina, como sua mãe, mas também envolvida na política. Em 2009, ela foi candidata independente (e infelizmente perdeu) nas eleições legislativas contra o líder nacionalista hindu do BJP, L. K. Advani. Tal dinastia feminina, feminista e envolvida na vida política eleitoral continua a ser um caso raro, se não o único no contexto político do subcontinente. Quando as mulheres herdam, é mais frequentemente dos homens e eles transmitem muitas vezes para os homens. Se o setor familiar for mais acessível para as mulheres, isso não significa, que não que exista qualquer forma de discriminação baseada no gênero. Ao contrário, esse modo de acesso aos mandatos políticos tem um custo.

\section{Da legitimidade familiar à legitimidade democrática}

A ideia de que a família e as representações simbólicas que the são associadas constituem um recurso importante para as mulheres é uma ideia muito importante generalizada na literatura dedicada a esta questão ${ }^{36}$. Por outro lado, raras são as reflexões sobre o custo desse recurso, que muitas vezes é

\footnotetext{
${ }^{34}$ Nossa informação sobre esta família vem de uma entrevista com Subhashini Ali (Deli, setembro de 2009), de um artigo desse último e da autobiografia de sua mãe. ALI, Subhashin."Uma vida em serviço". In: SEMINAR, 540, 2004 (http://www.indiaseminar.com/2004/540/540\%20subhashini\%20ali.htm) (acessado em 29 de agosto) 2016).

SAHGAL, Lakshmi. Vida revolucionária. New Delhi: Kali for Women, 1997

35 Nota tradutora: Subhashini Ali Seghal é neta de Ammu Swaminadhan.

${ }^{36}$ BASU, A. "Mulheres, dinastias e democracia na Índia", op.cit.

RICHTER, L. “Explorando as teorias da liderança feminina no sul e sudeste Asiático", op. cit., p. 527.
} 
ambivalente, não só porque se encaixa em hierarquias familiares desfavoráveis para as mulheres, mas também porque pode pôr em causa a legitimidade democraticamente das eleitas.

\section{A família como um recurso}

A vida política sul asiática é em grande parte masculina, especialmente quando se trata dos parlamentares. Se a participação política das mulheres é a partir de agora raramente criticada de maneira aberta na Índia, ainda existem formas importantes de discriminação contra elas e o "trabalho do eleito" ainda é frequentemente associado a valores e qualidades consideradas como masculinas (disponibilidade, mobilidade, facilidade de contato $)^{37}$. Como resultado, a entrada de uma mulher na política pode ser experimentada como uma transgressão, ou, em todo caso, como uma tomada de risco desnecessária para ela que pode acabar em situações desagradáveis. Ao apresentar uma tradição familiar, as mulheres podem mais facilmente justificar sua ambição política. Uma deputada independente, eleita na eleição parcial organizada em seguida ao falecimento de seu marido, explicou o seguinte: "durante vinte e dois anos, [meu marido] cuidou da sua circunscrição (...). Todo o desenvolvimento que foi feito em nossa circunscrição, é o resultado do trabalho do meu marido (...). Eu sou sua esposa, então eu entendo suas ideais, é por isso que eu decidi me candidatar nas eleições" (entrevista 65, 2011).

Além disso, ao estar no registro familiar, as mulheres eleitas podem usar figuras evocativas; a da irmã, a da esposa, a da filha e a da mãe. Por isso, a imagem da "família estendida" como um recurso ao mesmo tempo material e simbólico, desenvolvido por Gail Minault para analisar o compromisso político das mulheres nos nacionalismos indiano e paquistanês, permanece relevante atualmente ${ }^{38}$. 0 uso do nome de família certamente não é exclusivo para aquelas que passaram pelo setor familiar (ou das mulheres), mas as herdeiras a ele têm particularmente recorrido. O cumprimento do dever familiar é então construído como uma obrigação social e não como a busca de interesses pessoais. Além disso, os estereótipos de gênero, como a imagem de uma esposa (ou filha) recatada e dócil, pode ter vantagens para as mulheres em um contexto de política de linhagem. Sua (suposta) falta de individualidade as tornaria todas particularmente capazes de subsumir o legado familiar ${ }^{39}$. Esse motivo é muitas vezes é invocado para explicar a escolha de Indira Gandhi pelos líderes do Congresso em 1966: ela era percebida como dócil e sem ambição pessoal marcada ${ }^{40}$.

\footnotetext{
37 DUTOYA, V. A representação da mulher nos Parlamentos da Índia e do Paquistão, op. cit., p. 430.

38 MINAULT, Gail (org). A família estendida: mulheres e participação política na Índia e no Paquistão. Columbia: South Asia Books, 1981.

39 DERICHS, C. e THOMPSON, R. (orgs). Dinastias e líderes políticas femininas na Ásia: gênero, poder e pedigree, op. cit., p. 15.

40 HELLMANN-RAJANAYAGAM, Dagmar. "As pioneiras: Durga Amma, o único homem no gabinete", ibid., p. 34.
} 
Além disso, a família constitui um espaço de socialização política em que as mulheres estão incluídas. Durante as entrevistas, várias mulheres eleitas escolheram mencionar a "atmosfera familiar" como um dos fatores de sua politização. A socialização familiar não se limita ao fato de que membros da família tenham mandatos políticos e muitos representantes eleitos que nós pudemos reencontrar mencionaram a importância do investimento político em organizações tais como os movimentos comunistas ou então o nacionalismo hindu. No entanto, essa socialização assume uma característica particular quando os mandatos estão em jogo, especialmente em contextos onde a segregação dos sexos é apropriada, porque neste caso, os homens não podem se aproximar diretamente de suas eleitoras. A necessidade das esposas e das filhas de gerarem relações com o eleitorado feminino foi particularmente mencionado pelos representantes eleitos que conhecemos no Paquistão, mas também regularmente na Índia. Neste contexto, as herdeiras são raramente iniciantes na política quando da sua eleição, e a família constitui um recurso não só para a obtenção de um mandato, mas também para a execução deste mandato, mas esse recurso, como dissemos, tem um custo.

\section{Condições e limites da legitimidade familiar}

É mais fácil ser eleita quando herdamos o poder político, mas o poder que se mantém, em muitos casos é limitado. Na verdade, um herdeiro não escolhe o ser e muitas vezes é dito que as mulheres têm ainda menos flexibilidade a este respeito. Assim, para C. Jaffrelot, as "herdeiras não entraram no cenário público pela ambição, nem mesmo por vontade própria, mas sob a pressão de líderes masculinos"41. Esta ideia de herdeiras desamparadas é problemática porque na realidade existem poucos elementos que permitem provar que as mulheres estão sob pressão ${ }^{42}$ ou que elas seriam mais importantes que os homens. É verdade que, entre as eleitas indianas, que encontramos, 7 (de 16) disseram que entraram para a política não por escolha, mas por dever familiar. No entanto, também encontramos este tipo de discurso nos homens, como este jovem deputado do BJP: "Eu realmente não queria entrar na política, neste momento, eu estava mais interessado no gerenciamento do cricket e em comandar uma empresa de exportação (...). Eu estava indo bem nessas duas áreas (...). Fui nomeado, e pela graça de Deus, ganhei com uma quantidade de votos recorde" (entrevista 49, 2009).

A entrada forçada de uma mulher nos apareceu apenas uma vez: durante a entrevista, o marido da deputada que deveríamos entrevistar nos disse que era ele quem havia decidido que ela iria candidatar-se ao Parlamento, enquanto ele iria investir na política local. A partir daqui foi ele quem deu a entrevista, sua

\footnotetext{
41 JAFFRELOT, C. "Índia, democracia dinástica ou democracia de linhagem?", op. cit., p. 144.

42 Isso parece mais atestado no nível local. JOHN, Mary E. "Mulheres no poder? Gênero, casta e a política de governança urbana local". In: Economic and Political Weekly, 42 (39), 2007, p. 3988.
} 
esposa não respondeu a nenhuma de nossas perguntas. Apesar das reais restrições que pesam sobre elas, as mulheres geralmente não são passivas nas situações de legado político, e podem atuar tanto sobre os desentendimentos que às vezes existem em sua família e no partido quanto na escolha do herdeiro. Um caso famoso é o da sucessão do líder Tamil Ramachandaran em 1988. Haviam então dois candidatos para sua sucessão, sua viúva Janaki Ramachandaran e sua amante, Jayalalitha. De início, a esposa foi reconhecida pelo partido de Ramachandaran como a presidenta legítima, mas como resultado após sua derrota nas eleições, deixou a política, e finalmente Jayalalitha impôs-se à frente do partido ${ }^{43}$. Este exemplo mostra que o esteriótipo da mulher política dependente dos entes queridos deve ser relativizado. Além disso, na medida em que tais representações de homens são raras, vale a pena sublinhar as implicações sexistas.

\section{O estigma da "equipe das filhas e das esposas"}

Os herdeiros e as herdeiras continuam a ser eleitos em proporções significativas, o que sugere uma forma de aceitação da dinâmica da linhagem pelo eleitorado. Ao mesmo tempo, esse fenômeno é regularmente criticado pelos meios de comunicação. Esta crítica não visa especificamente as mulheres, mas é de gênero. Em particular, a imprensa frequentemente se refere à "brigada beti-biwi"44, a "equipe das filhas e das esposas ", e nunca a de filhos e maridos. Esta crítica é particularmente importante no contexto do debate sobre as cotas de mulheres que se cristalizaram no final da década de 1990 em torno do projeto de lei Cota de Reservas para Mulheres. De acordo com este projeto, um terço dos assentos nas assembleias dos Estados e da Câmara Baixa Central deveriam ser reservados para as mulheres. Muitas poucas vozes se levantaram para questionar a legitimidade da participação política ou das cotas das mulheres como tal, mas muitas vozes têm sublinhado o risco de se eleger "mulheres ruins", isto é, proxies ${ }^{45}$ ou nomes prontos. Assim, quando os assentos reservados no nível local foram disponibilizados na década de 1990, surgiu a expressão sarpanch pati (literalmente o "prefeito-marido") para designar aqueles que governariam através de suas esposas. Este argumento é usado pelos opositores da aplicação de cotas para mulheres a nível nacional. Assim, para um deputado do Congresso (do partido que apoia o projeto de lei), devido às cotas, os assentos poderiam ser atribuídos "aquelas que não o merecem" (entrevista 55, 2009). Contraditoriamente, ele mesmo deve seu lugar ao pai dele.

\footnotetext{
${ }^{43}$ CAVERLAN, R. "Dinastias políticas da Índia Central", op.cit., p. 80.

44 Nota tradutora: a expressão "brigada beti-biwi" refere-se ao nível de autonomia das mulheres para exercerem suas legislaturas devido a subordinação que elas sofrem nos lares, assim elas na verdade sendo eleitas representariam os interesses de seus parentes masculinos. Fonte: KEATING, Christine. Decolonizing democracy: transforming the social contract in India. Pensilvânia: Pensilvania University Press, 2011.
}

${ }^{45}$ Nota da tradutora: proxy seria a pessoa que agiria como a intermediária de outras pessoas. 
Os homens não são poupados pela crítica das dinastias políticas, mas isso geralmente se relaciona com a questão dos privilégios que teriam desfrutado, não a de sua autonomia como pessoa eleita ${ }^{46}$. Um pesquisador e ativista defensor da causa das mulheres escreveu que as "mulheres que alcançaram a vida política através de suas conexões familiares tendem a ser usadas como proxies - uma posição que até mesmo o menos talentoso dos homens não se deixaria impor"47. Parece inconcebível que uma boa esposa, uma filha ou uma irmã não consulte seus parentes antes de tomar uma decisão política qualquer. Este discurso é paradoxal, na medida em que onde o apelo à feminização da vida política baseia-se no postulado normativo que isso melhorará a democracia, tornando-a mais inclusiva e justa, lhe agregando os valores que seriam tipicamente femininos. Neste contexto, a tensão entre a lógica familiar e a lógica democrática é fortalecido; as famílias políticas são criadouros importantes de candidatas potenciais, mas o uso de tais métodos vai ao encontro da lógica democrática para uma suposta feminização da política. $\mathrm{O}$ fato de ser "esposa" ou "filha" pode atenuar a transgressão do exercício do poder político por uma mulher, mas reforça a transgressão que constitui a família em relação à ordem democrática.

O contributo do conceito de gênero para a ciência política é triplo; empírico, metodológico e teórico ${ }^{48}$, e o estabelecimento de uma reflexão de gênero sobre a hereditariedade política o ilustra bem. Prestando atenção ao sexo dos indivíduos (e à economia de gênero de suas relações), temos uma visão mais fina da transmissão familiar do poder político que reflete as relações de poder que são jogadas dentro da família. No nível teórico, o contributo da análise de gênero parece particularmente forte. Na verdade, a transmissão do poder político pela família questiona a autonomia do campo político. Paradoxalmente, a observação do fenômeno do ponto de vista do gênero, e mais particularmente da posição das mulheres, reafirma essa autonomia, uma vez que a família pode ser um espaço para reprodução de normas de gênero desiguais e da transmissão de poder político para as mulheres, sem que as duas atividades pareçam se contradizer uma contra a outra. Na verdade, não há uma transformação radical do estatuto das mulheres nas famílias onde há herdeiros políticos ou a afirmação feminista em particular.

Finalmente, é importante voltar à aparente contradição entre a imagem das mulheres como salvadoras da democracia e aquela das herdeiras coveiras da mesma democracia. Essa contradição destaca a persistência das representações de gênero no campo político e as ambivalências do discurso igualitário. $\mathrm{Na}$ verdade, a ideia de que as mulheres renovarão a vida pública e fortalecerão a democracia baseia-se ao mesmo tempo sobre o ideal igualitário das representações diferenciadas de gênero, que fazem das mulheres depositárias de qualidades específicas (gentileza, preocupação com os outros, humanas, etc.) que

\footnotetext{
${ }^{46}$ HELLMANN-RAJANAYAgAM, Dagmar. "As pioneiras: Durga Amma, o único homem no gabinete", ibid, p. 46.

${ }^{47}$ KISHWAR, Madhu. "Mulheres e política: entre cotas". In: Economic and Political Weekly, 31 (43), 1996, p. 2873.

48 JENSON, Jane e LEPINARD, Eleonore. "Pensando em gênero na ciência política: para uma tipologia dos usos do conceito". In: French Review of Political Science, 59 (2), 2009, p. 201.
} 
elas teriam forjados para seu engajamento privilegiado em uma esfera definida como privada e doméstica ${ }^{49}$. No entanto, assim que elas demonstrarem seus "valores familiares" favorecendo seus entes próximos, ou simplesmente os incluindo nos arredores políticos, isto é visto como prova de sua incapacidade de serem representantes políticas autônomas.

49 DIETZ, Mary. "Contexto é tudo: feminismo e teorias da cidadania". In: MOUFFE, Chantal (org). Dimensões da democracia radical: pluralismo, cidadania, comunidade. Londres: Verso, 1992, p. 63-85. 